\title{
Los mitos literarios y su trasvase al cine. Hacia un nuevo paradigma posterrorífico: la socialización del monstruo
}

\section{Literary myths and their transfer to the cinema. Towards a new post-terrifying paradigm: the socialization of the monster}

\author{
Pedro Pujante \\ Universidad de Murcia \\ pujante1000@hotmail.com \\ ORCID ID: 0000-0002-2047-3548
}

\begin{abstract}
Resumen: En el presente artículo se pretende discutir brevemente sobre la evolución que la figura estética de tres de los monstruos clásicos (vampiro, zombi y demonio), provenientes de la literatura, ha experimentado en el cine, para reflexionar sobre cómo se ha construido un bestiario contemporáneo radicalmente renovador, sin perder de vista su naturaleza literaria. Como aquí trataremos de mostrar, en los últimos tiempos su total asimilación ha provocado que en algunas ficciones literarias y audiovisuales la crisis de la monstruosidad haya devenido en una ruptura de la alteridad, es decir, los "otros" han sido incorporados al "nosotros" y dejado de ser contemplados como extraños, y el terror sobrenatural se ha sustituido por una problemática de carácter social.
\end{abstract}

Palabras clave: literatura de error, cine de terror, mitocrítica, monstruos, series, fantástico.

\begin{abstract}
In this article we intend to reflect briefly on the evolution that the aesthetic figure of three of the literature classic monsters (vampires, zombies and demons) has experienced in the cinema, in order to reflect on how a radically renewing contemporary bestiary has been constructed both in cinema and literature. As we will try to show here, in recent times their total assimilation has caused that in some audiovisual and novelistic fictions the crisis of the monstrosity has become a rupture of alterity, that is, the "others" have been incorporated into the "our-Self", and ceased to be regarded as strangers. Besides, the supernatural terror has been replaced by social preoccupations.
\end{abstract}

Keywords: horror literature, horror cinema, mitochritic, monsters, series, fantastic. 


\section{INTRODUCCIÓN}

Existe un consenso en establecer que el concepto de "fantástico" evoluciona y está en gran medida determinado por la época y la cultura en que la obra está inserta. Si bien es cierto que para que se produzca el efecto de lo fantástico ha de quebrantarse, transgredirse o alterarse el tejido de lo real (Roas, 2011; Campra, 2011; etc.), hay que asumir que lo que consideramos real es siempre relativo y varía con el transcurso del tiempo. El contexto social, político y cultural condiciona y redefine la estética de la ficción fantástica. Los avances científicos alumbran zonas oscuras que habían permanecido ocultas, y lo que en un pasado se consideraba una intervención por parte de fuerzas sobrenaturales es más adelante explicado desde los presupuestos de la ciencia, las matemáticas o la física. Esto es más evidente en los discursos fantásticos que en otras ficciones, ya que el efecto fantástico se ve determinado y, hasta cierto punto, condicionado por su tiempo y su ecología cultural, y, por tanto, redefinido constantemente por factores extratextuales. Como ha explicado el profesor David Roas, «lo fantástico, por tanto, debe estar inscrito permanentemente en la realidad» (2001: 25). Lo que hace un siglo se consideraba fantástico hoy es ciencia, y lo que hace tan solo diez años parecía una quimera o descabellada ciencia ficción hoy ya es tecnología obsoleta.

A pesar de estos cambios drásticos en las ficciones fantásticas se siguen manteniendo intactos algunos de sus protagonistas más emblemáticos. Personajes principales de relatos fantásticos han sido y siguen siendo los monstruos. En gran medida ilustran y encarnan la maldad, la otredad, y también son los representantes de ese mundo tras la frontera de lo real, los habitantes habituales de lo fantástico. En este sentido, es nuestra intención reflexionar en este artículo sobre cómo han evolucionado los monstruos desde la literatura hasta llegar a nuestros días, especialmente a través del cine, y cómo se representan en algunas películas y series de televisión en las que monstruos canónicos, como son el zombi, el vampiro y el demonio, han sufrido una evolución radical $\mathrm{y}$, por tanto, han sido alterados en lo que se refiere a su recepción epistemológica. En los ejemplos que aquí comentaremos se plantean algunas situaciones en las que estos tres modelos clásicos de la literatura y el cine de terror han derivado en situaciones "posterroríficas", ya que los efectos de terror o sobrenaturales que producían han sido totalmente asimilados (incluso obliterados) y la sociedad, mientras se enfrenta a ellos, los combate y los supera, tiene que arrostrar otros problemas nuevos que de estos derivan. Así, el terror sobrenatural, que proviene de lo desconocido, deja de tener sentido en sí mismo en tanto estas entidades han sido incorporadas al tejido social, pierden su poder de extrañamiento y devienen elementos socialmente aceptados. La brecha, incluso la vacilación todoroviana, que caracteriza lo fantástico, ha sido cerrada y nos encontramos con escenarios que nos remiten a poéticas neofantásticas o de ciencia-ficción, cronotopos 
que se caracterizan por asimilar lo fantástico como parte de la "realidad", entremezclando elementos imposibles con otros de naturaleza cotidiana.

La literatura fantástica, como sabemos, tiende a inscribirse en la realidad. Si los relatos fantásticos clásicos proponían una dicotomía entre lo real y lo imposible y señalaban una línea divisoria para después traspasarla o violentarla, se constata una tendencia a insertar lo fantástico en lo cotidiano porque así el efecto es mucho mayor. En el siglo XX éramos testigos de una nueva tendencia en lo fantástico, sobre todo tras Kafka, donde la realidad ya no solo era violentada sino que acababa por volverse fantástica. Jaime Alazraki ha venido a definir este nuevo marchamo literario como "neofantástico". Y una de sus características principales pasa por sustituir el factor terrorífico por la provocación de perplejidad o inquietud. Además, los discursos fantásticos literarios y fílmicos procuran ser cada vez más verosímiles porque el lector/espectador asimila los códigos a gran velocidad y el género automatiza fórmulas que acaban por volver el relato previsible y le hace perder su efecto fantástico. Podríamos sostener que el escarabajo-Samsa creado por Kafka es el primer monstruo posterrorífico, o al menos un precursor de este cambio de paradigma que aquí analizamos, ya que como explica Alazraki (1983), la vacilación se anula y además el hecho fantástico queda inscrito en la realidad. El terror metafísico se convalida por una situación absurda en la que la preocupación social y familiar se sitúa en el centro del relato.

Para evitar la automatización de fórmulas y renovar los escenarios de terror tradicionales, algunos cineastas, guionistas y escritores han ideado novedosos contextos en los que el terror ha sido sustituido por un "posterror", término que aquí traemos para explicar recientes ficciones en las que la presencia del monstruo no solo ha sido ya asimilada, y su problemática (su efecto perturbador y terrorífico) trascendida, sino que la sociedad y el individuo coexisten con él en evidente "armonía". La tríada que conforma el bestiario clásico de la mitología de terror contemporánea (vampiros, zombis y demonios), en los filmes y series que aquí consideraremos, son trascendidos y el individuo ya no es espantado por ellos ni sufre su presencia a título personal. El escándalo provocado por lo desconocido (como el efecto fantástico), entonces, ha sido suplido por un "posterror", caracterizado este por acaecer en un escenario en el que se ve afectada la esfera social (y no tanto la subjetividad del protagonista), en un ecosistema abierto en el que cambia el problema y se expande a otros círculos menos restringidos, con incidencias menores en lo psicológico y más en lo sociológico. Es decir, el trauma individual lo sustituye un trauma colectivo, y los conflictos psicológicos/paranormales se extienden y problematizan otros ámbitos socioculturales. Así, se plantean relatos basados desde nuevos discursos y ópticas. Este cambio radical de paradigma se debe, entre otros motivos, a la paulatina secularización de la sociedad, situación que evidencia una diferenciación cultural modulada por 


\section{Pedro Pujante}

discursos alejados de lo supersticioso y lo religioso. Rosemary Jackson reflexiona sobre el diálogo de lo fantástico con lo cultural y afirma que «en una cultura secularizada, el deseo de lo otro no se desplaza hacia regiones alternativas del cielo y el infierno, sino que se dirige hacia las zonas ausentes de este mundo, transformándolas en "otra" cosa, diferente de la familiar y confortable» (1986: 17). Así pues, es comprensible que en un mundo cada vez más secularizado y desembarazado en gran medida de sólidos agentes religiosos que promuevan un sustrato cultural de intensa espiritualidad, basado en credos y dogmas y una visión teocéntrica de la vida, la ficción fantástica haya abandonado sus vínculos iniciales con lo espiritual y apele a un cuestionamiento más afín a la sociedad o la propia cotidianidad.

\section{CAMbio de PARAdigma: El MONSTRUO es COMO NOSOTROS}

El monstruo, explica Ana Casas en Las mil caras del monstruo, «no es un ser estático, sino que evoluciona con el correr de los tiempos, cambia según sea una u otra su localización histórica o geográfica» (2012: 10). Como señala, por otra parte, Trapero Llobera, el «monstruo servirá para reflexionar acerca de la cara oscura de la sociedad, de la moral y la ideología que operan culturalmente» (2015: 70-71). Así, observamos, por una parte, una «domesticación de monstruo», según expresa David Roas, y también una instrumentalización del monstruo como artefacto de reflexión social, que ha sido traducido a códigos contemporáneos y reconvertido en un ser que no es fuente de terror supersticioso sino, más bien, un agente social disruptivo. Este cambio de paradigma no es accidental ni súbito, y se viene gestando desde hace ya varia décadas, como se nos muestra en sagas cinematográficas como Blade (1998-2004), protagonizada por un híbrido humano-vampiro heroico; o Underworld (2003-2016), en la que humanizados vampiros luchan contra los hombres lobo; o en la serie American Horror Story (2011-2018), en la que los monstruos son los protagonistas $\mathrm{y}$, en gran medida, han comenzado a humanizarse. Este cambio de paradigma reescribe una tradición y la sustituye por una nueva estética que tiende a «la caracterización de los monstruos como seres muy cercanos a los humanos con los que pueden llegar a confundirse» (Platts, 2014). Sin embargo, es posible remontarse más si cabe para comprender esta "secularización de lo fantástico". Desde la citada La metamorfosis (1915) de Franz Kafka ya se advierte una tendencia a construir un monstruo con otros fines distintos a la historia de terror fantástica, más al servicio de una reflexión sociológica, ética o metafísica. Herederos de Kafka son también los relatos neofantásticos hispanoamericanos, en los que se asimila lo extraño para dar paso a una visión de la realidad en la que la trasgresión (de esta realidad) no está en el centro del relato. Es interesante descubrir que tanto en las narraciones posterroríficas que aquí examinamos y algunos relatos neofantásticos (por ejemplo "Casa tomada", de Julio Cortázar) los protagonistas se han 
acostumbrado a una situación de por sí anómala y aprenden a convivir con ella, resultando el miedo a lo desconocido sustituido por otra nueva situación que de esa intrusión de los "otros" se ha derivado.

Es comprensible que algunas formas narrativas contemporáneas hayan mutado en una revisión de los arquetípicos monstruos y los hayan reutilizado desde una nueva perspectiva. El vampiro, por ejemplo, es una paradigmática figura que tiene sus antecedentes literarios en los relatos $E 1$ vampiro (1849) y La familia del Vurdalak (1839), ambos de Alekséi Konstantínovich Tolstói, y sobre todo en El vampiro (1819) de John Polidori y que, posteriormente, se convirtió en un monstruo ampliamente conocido y popular gracias al Drácula (1897) de Bram Stoker. Recordemos que el vampiro es un no-muerto, alguien que fue humano pero que dejó de serlo, gracias a la intervención de fuerzas sobrenaturales, normalmente de origen demoníaco y oscuro. El no-muerto, al haber sido un humano previamente, no deja de mostrarse con una monstruosidad ambigua, ya que siempre se percibe como mitad hombre, mitad monstruo. No obstante, la tradición literaria y después la fílmica han insistido en aleccionarnos de que esa porción de naturaleza humana, tras la muerte y posterior mutación vampírica, era eliminada totalmente y sustituida por la dominante naturaleza infernal. A pesar de ello, los vampiros que resultan atractivos no han dejado de aparecer una y otra vez en la ficción. Desde el Conde seductor, pasando por bellas seductoras vampiresas que son caracterizadas con un erotismo magnético y que tienen su origen romántico en Carmilla (1872), de Joseph Sheridan Le Fanu, y en La morte amoureuse (1836), de Théophile Gautier. De hecho, a pesar de su condición de monstruos, el cine de serie B (a partir de los productos de la Hammer, sobre todo con Christopher Lee como conde Drácula) ha insistido en ofrecernos una visión romántica y sugerente del vampiro, que a diferencia del monstruo horrendo de su antecesor más stokeriano Nosferatu, está dotado de expresiones humanas, raciocinio y elegancia.

Uno de los monstruos que con mayor flexibilidad se ha ido adaptando al signo de los tiempos es el vampiro. Como señalan Joan Gordon y Veronica Hollinger en la ficción vampírica contemporánea las barreras entre lo humano y lo monstruoso son cada vez más delgadas y confusas (1997: 2-5). Esta "humanización" del vampiro, como veremos, se ha ido intensificando a lo largo del tiempo, y cada vez son más los filmes y las novelas que recurren a esta reconversión del monstruo en un ser cercano a nosotros, dotado de emociones, de palabra e incluso de belleza. Así, no solo se le hace más humano, sino que se le despoja de su sentido maligno y, en definitiva, de su naturaleza terrorífica. Series, novelas y películas actuales no dudan en representar al típico vampiro como un adolescente enamorado y atribulado por las vicisitudes de la sociedad en la que vive. El vampiro ha sido enteramente subsumido por nuestra sociedad de consumo y su imagen, totalmente actualizada, ha devenido en icono cultural. Como sostiene Alicia Nila Martínez Díaz, hoy día asistimos a la «vampirización 
del mito del vampiro», ya que este se ha corrompido y perdido su fuerza original o, al menos, este ha sido reducido (2010). Ya se percibe esta tendencia en el filme de Coppola Bram Stoker's Dracula de 1992, que a pesar de mantener muchos de los rasgos del vampiro tradicional (fealdad, avidez por la sangre, poderes sobrenaturales y vínculos con lo oscuro) también es puesta de manifiesto su faceta más romántico-sentimental.

Es la escritora Anne Rice quien con Entrevista con el vampiro (1976) inicia un ciclo novelístico paradigmático en el que el vampiro protagonista toma la palabra y, de este modo, en primera persona, narra sus vicisitudes a lo largo de siglos de "vida". Este procedimiento consigue distanciar al nuevo vampiro del clásico, intercambiando la vertiente religiosa (el vampiro se considera ateo, nihilista) por un planteamiento filosóficoexistencial; la faceta monstruosa por otra más "humana" (el vampiro habla y muestra sus sentimientos y sufrimientos al asesinar) y, finalmente, autoconsciente de su naturaleza inmortal pero no-humana que le condena a vagar por el resto de la eternidad, sin una familia real y sin relaciones afectivo-sexuales normales. Esta visión neorromántica del vampiro es también explorada por el cineasta Jim Jarmusch en Only lovers left alive (2013). Aquí se narra la relación entre una pareja de amantes vampiros, Eve y Adam, que son presentados como sofisticados, sensibles, cultos e intelectuales. La evolución los ha llevado a dejar de matar y se proveen de hemoglobina saludable desde los hospitales, ya que los humanos están cada vez más contaminados volviéndose tóxica su sangre.

Otro ejemplo reciente que muestra con gran nitidez la progresiva humanización del monstruo lo podemos hallar en el filme noruego Déjame entrar (2008), de Tomas Alfredson, y basado en la novela de John Ajvide Lindqvist, quien también firmara el guion. Esta cinta, si eliminamos la naturaleza vampírica de la niña protagonista, puede ser considerada una pieza de cine social. El argumento trata de un niño llamado Oskar que vive en un suburbio de Estocolmo. El joven es víctima de abusos por parte de sus compañeros de colegio. Un día llega al vecindario una niña llamada Eli (que resulta ser una vampira) acompañada de un adulto, quien la provee de sangre y cuida de ella. La cinta, con una factura melancólica y oscura, examina las relaciones entre los dos niños. Esta postura nos muestra la inocencia del monstruo, así como su vulnerabilidad en un inhóspito mundo de adultos-humanos, en una sociedad en la que no hay lugar para marginados o diferentes. Independientemente de la carga social y emocional del relato, nos interesa destacar cómo se construye una figura vampírica a través de los tópicos del inadaptado, del niño huérfano y de la identidad preadolescente. Es decir, mediante correlatos propiamente humanos, realistas y sociales. Con los mismos ingredientes (crítica social, personajes inadaptados y fantásticos) se construye la película Border (2018), de Ali Abbasi, también basada en un relato y con guion de John Ajvide Lindqvist. En esta peculiar fantasía social los protagonistas son troles (alguno no sabe su naturaleza hasta el final de la película) que habitan en el 
mundo de los humanos y que tratan de conservar sus raíces ancestrales, amenazadas por la sociedad humana. No es este el lugar para discutir en profundidad el filme y sus subtramas y argumento, pero sí que conviene remarcar que en ella el monstruo cobra el estatus de personaje principal al que se le otorga la voz y que capitaliza la perspectiva narrativa de los acontecimientos. El monstruo aquí es un outsider y no es asimilado por la sociedad, es cierto, sino que es él quien, en un giro totalmente inusual en la narrativa fantástica, ha asimilado la "conciencia de clase" humana y vive según sus reglas y costumbres. También es reseñable cómo el cine social se apropia de los tópicos, personajes y fórmulas de los relatos fantásticos construyendo una nueva visión de lo fantástico donde confluyen las preocupaciones sociales y temas de actualidad como la pornografía infantil, la inmigración o las relaciones familiares.

Regresando al tema que nos ocupa, recordemos que los vampiros, además del terror sobrenatural que causaban porque podían robar tu alma inmortal y condenarte a vagar como un espectro por el resto de la eternidad, suponían un problema de orden práctico: ocasionaban un gran número de muertes y desapariciones, una alarma social. La causa es sencilla: necesitan tu sangre para alimentarse. Pero, ¿qué ocurriría si este problema se eliminase de la ecuación gracias a la creación de una sangre sintética? Este es el escenario que se plantea en la serie televisiva True Blood (2008-2014), basada en las novelas que forman The Southern Vampire Mysteries (2001-2013), de Charlaine Harris. En esta serie se parte precisamente de esa premisa: se ha comenzado a comercializar una sangre sintética diseñada por científicos japoneses. De este modo los vampiros pueden "salir del ataúd" e integrarse en la sociedad. Por supuesto la aceptación de los otros nunca es total y los monstruos (cada vez más humanizados) son todavía víctimas del rechazo por parte de un amplio sector de la sociedad. Un ejemplo de este incipiente cambio de paradigma, en el que el monstruo trata de ser reconocido socialmente, ya está latente en el personaje de Frankenstein de Shelley o, por mostrar un ejemplo más concreto y reciente, lo encontramos en el segundo capítulo de la cuarta temporada de American Horror Story cuando afirma el personaje de Jimmy Darling, un freak deforme: «Don't call me freak. If they just go to know us, they would see that we're just like them».

El terror al vampiro, por consiguiente, es, en estas ficciones últimas, transformado por una suerte de xenofobia, y el temor individual y místico deviene en problemática social y cultural. Esta veta "postvampírica" también ha sido explotada en películas como Daybreakers (2009), en la que se lucha por encontrar una cura para el vampirismo; o en la cuarta temporada de la serie creada por Guillermo del Toro y Chuck Hogan, The Strain (2014-2017), adaptación de la novela Nocturna (2009), en la que tras una explosión que provoca una nube que oscurece el planeta, los vampiros se hacen con el poder sobre la Tierra y someten cruelmente a los humanos, de los que se alimentan, transformando la sociedad en una 


\section{Pedro Pujante}

dictadura vampírica despiadada, con ecos de la obra de Matheson I Am Legend (1954). A pesar de las grandes diferencias entre los aristocráticos vampíricos de Stoker y las nuevas razas de vampiros contemporáneos, siguen las dos manifestaciones coincidiendo en su aspiración a la inmortalidad y en su supremacía social respecto a los humanos. No hemos traído aquí ficciones como Crespúsculo, porque a pesar de que el vampiro se ha humanizado (incluso banalizado hasta extremos ridículos) y vive entre nosotros, sigue escondiendo su identidad real ante la sociedad y, por consiguiente, perteneciendo al mundo de lo desconocido.

De un modo análogo se desarrolla y plantea la británica miniserie televisiva In the flesh (2013-2014), creada por Dominic Mitchell, aunque esta vez el monstruo protagonista es el zombi. Una figura popularizada por George Romero y que desde sus orígenes se proponía como una metáfora de la discriminación social. Si bien es cierto que el zombi ha evolucionado desde una etapa vinculada al vudú haitiano, pronto fue absorbido por la industria cinematográfica y se difundió como el monstruo vaciado de conciencia e identidad y multitudinario que hoy conocemos. De hecho, si algo sirve para vincular a los primeros zombis vudú (por ejemplo, I Walked with a Zombie, Jacques Tourneur, 1944) con los más recientes infectados (28 Days Later, Danny Boyle, 2002), es que «todos ellos han sido previamente despojados de sus funciones mentales básicas, quedando a merced de fuerzas que no pueden controlar» (Sánchez Trigos, 2013: 15); es decir, carecen de voluntad, de un yo que los haga seres con identidad propia. El zombi representa a la muchedumbre, al ser anónimo, al paria de una sociedad alienada que ha dejado que sus individuos se conviertan en seres autistas, incomunicados, que vagan formando masas amorfas e inadaptadas que amenazan nuestra forma de vida. El zombi es el representante moderno de la otredad y si el vampiro encarna al aristócrata, el muerto viviente hace lo propio con las clases medias y bajas. En las tres etapas que detallan Boluk y Lenz, ya se advierte que «la tercera y última etapa [...] describe al zombi como un ser humano patológicamente infectado» (2008: 3). Es decir, su monstruosidad ha sido capitalizada por motivos científicos y no místicos. Sus motivaciones son evidentes para la sociedad y no forman parte de un mundo oculto y sobrenatural. Ha pasado el zombi de representar al ser sin alma a encarnar la ausencia más absoluta de identidad del hombre contemporáneo, el hombre anónimo.

In the flesh nos sitúa en un mundo que podríamos llamar más posterrorífico que postapocalíptico, en el que ya se ha erradicado la enfermedad contagiosa que convierte a los humanos en muertos vivientes, gracias a un fármaco. De este modo, el problema (ya no sobrenatural sino médico) radica en integrar de nuevo en la comunidad a la que pertenecían a los afectados por el Síndrome de Fallecimiento Parcial (Partially Deceased Syndrome o PDS), un término eufemístico que funciona como fórmula para desplazar semánticamente el terror sobrenatural por códigos 
médico-sociales. Este proceso de adaptación no es sencillo porque los recuperados del PDS habían sido anteriormente "monstruos" irracionales que devoraban y asesinaban a miembros de su comunidad, lo que ocasiona un enorme rechazo, pero también espanto, por lo que se mantiene gran parte del terror que los zombis clásicos producían. De hecho, la medicación contra el PDS no es definitiva, tan solo paliativa y cuando se suspende su consumo, el afectado se convierte de nuevo en un "monstruo" peligroso y antropófago. Aquí se perciben paralelismos con los adictos a opiáceos, a los yonquis callejeros dependientes de la metadona que despiertan desprecio y desconfianza entre los miembros de las sociedades contemporáneas, aunque en el caso de los afectados del PDS, paradójicamente, a pesar de no ser responsables de su "enfermedad", portan el estigma de haber sido asesinos feroces. El mismo planteamiento de esta serie ha sido llevado al cine en el filme The cured (2017), de David Freyne.

Aunque estas materializaciones del zombi puedan parecer novedosas, no cabe duda de que la transformación de la figura del monstruo-zombi se ha venido gestando desde sus mismos orígenes. El zombi, a diferencia del resto de monstruos, ha supuesto una alarma social desde el comienzo, desde la primera cinta de George Romero. Por supuesto que al principio los humanos vueltos a la vida todavía suponían una ruptura con lo real que nos enfrentaba ante el hecho fantástico. Cabe recordar que, a pesar de que ya la primera incursión en el universo zombi de Romero, contaba con grandes dosis de crítica social (desde ese protagonista afroamericano), la primera escena tiene lugar en un cementerio, lugar característico de las narraciones de terror decimonónico. Pero en la filmografía del propio Romero ya advertimos esa evolución que aquí queremos analizar, aunque de un modo bastante esquemático. En sucesivas entregas, el número de zombis aumenta y el mundo se transforma en un lugar infestado por las antropófagas criaturas cuya proporción es muy superior al número de humanos, los cuales, incluso, han de vivir en estados de tipo feudal para protegerse de la amenaza zombi. Este escenario postapocalíptico lo vemos en Land of the Dead (2005), la cuarta entrega de la saga zombi de Romero. Aquí la sociedad, debido a la infestación de muertos vivientes que asola el mundo, se convierte en un universo distópico, estableciéndose un tipo de sociedad de castas seudomedieval, en la que las diferencias entre ricos y pobres se acentúan con gran intensidad. Aunque esta película no es posterrorífica en el sentido que nosotros aquí entendemos, sí que muestra algunos de los antecedentes de este tipo de narraciones. Por un lado, la sociedad ya comienza a asimilar a los monstruos como un fenómeno problemático y no tanto como una amenaza sobrenatural. Además, la humanización del monstruo cobra vital importancia en la trama. De hecho, uno de los zombis, conocido como "Big Daddy" (que tenga nombre propio es relevante y merece la pena subrayarlo), muestra autoconciencia de su naturaleza, maneja armas de fuego y enseña a sus compañeros muertos a 
utilizarlas. Esta capacidad de aprendizaje, exclusivamente humana, es una clara evolución de la figura del monstruo, inédita hasta la fecha en el desarrollo del zombi tradicional. "Big Daddy" es inteligente, cooperativo y capaz de liderar un ejército de muertos vivientes, demostrando ser consciente de su condición, además de mostrar un alto nivel de empatía hacia sus congéneres. Esta autoconciencia es evidente en otros zombis de la película: una animadora que agita los pompones, un músico que trata de soplar su corneta o una pareja de muertos vivientes que continúan cogidos de la mano. Así no solo se humaniza al monstruo, también se ahonda en la idea de que "los otros somos nosotros", a la vez que se incide en metaforizar las diferencias sociales entre ricos y pobres, entre parias y privilegiados.

Pero quizá la serie que de forma más original ha traído el tema de los muertos vivientes para plantear un dilema de orden social (y también familiar) sea Les Revenants (2012-2015). Esta serie francesa, creada por Fabrice Gobert, consta de tan solo dos temporadas. En el pueblo de Annecy los fallecidos han comenzado a regresar a su casa después de varios años desde su defunción y entierro. Lo terrorífico es, de algún modo, relativizado debido a que los "regresados" o "aparecidos" aparecen con el mismo aspecto y edad que tenían el día de su fallecimiento. Este inusual e inexplicable evento causa, como es evidente, gran revuelo y conmoción en la tranquila comunidad francesa. Que los fallecidos regresen con apariencia totalmente humana hace que, a diferencia de los zombis tradicionales, no causen rechazo. Además, los revenants pueden hablar y recordar sus experiencias previas a la muerte, y se comportan como "seres humanos de carne y hueso". Esta paradójica situación es el punto clave que hace de esta serie posterrorífica una de las narraciones con más complejidad tanto social como emocional. Los dilemas que se plantean son de carácter técnico: ¿dónde han de vivir si sus familiares han rehecho sus vidas o ya han fallecido? ¿Quién se hace cargo de su manutención y cuidado? Derivan de esta situación grandes cuestiones humanitarias y socioeconómicas. Pero sobre todo, aquí hay que subrayar la gran relevancia que adquieren los dilemas éticos y emocionales. ¿Qué lugar ocupa el exnovio fallecido en la nueva relación de su antigua pareja con el nuevo esposo? ¿Qué sentimientos despierta la reaparición de un niño fallecido hace varias décadas en unos padres o familiares que ya han transitado por el duelo y que tratan de vivir sus vidas a partir de aquellas pérdidas?

En cualquier caso, esta serie en la que la humanización del monstruo es más bien una monstruoficación del ser humano, sigue conservando los elementos del género de terror intactos, y la problemática social no diluye para nada el elemento sobrenatural, el misterio y, por tanto, también el efecto fantástico en cuanto a ruptura del tejido de lo real. Sus presencias, a pesar de ser humanas y reconocibles por todos (o quizá más si cabe por esto mismo, como también provoca pavor la figura del Doble), siguen causando estremecimiento entre los vecinos. Y, sin duda, también entre 
los telespectadores, quienes no pueden dejar de establecer vínculos entre lo familiar de la situación y lo siniestro que en ella subyace. Explicaba Freud en su famoso estudio Das Unheimliche (1919) que lo siniestro puede ser producido con el regreso de los muertos a la vida; y más adelante, refiriéndose a la creación artística sostenía Freud que el efecto siniestro es más potente cuando «el poeta aparenta situarse en el terreno de la realidad común», y que este (el poeta) "puede exaltar y multiplicar lo siniestro mucho más allá de lo que es posible en la vida real, haciendo suceder lo que jamás o raramente acaecería en la realidad» (1992: 249). Esto es más que evidente en la factura de esta narración, en la que la realidad más trivial se ve, de pronto, subvertida por un acontecimiento tan siniestro como la vuelta a la vida de los muertos. Y además, con la particularidad de que estos "muertos" están "vivos". Su amenaza consiste en desmantelar el orden social y emocional de los habitantes de Annecy, una comunidad cerrada y aislada, pero que de algún modo sirve de espejo en el que reverbera la propia naturaleza humana. Hay que matizar que estos revenants se acogen mejor a la descripción de fantasma o espectro que a la de zombi propiamente dicho. No comen carne, hablan y, aunque no carecen de corporalidad, su naturaleza siniestra parece evocar más al alma del fallecido, a su espíritu (aunque sea simbólicamente), que al propio fallecido.

El monstruo que culmina la tríada clásica es el demonio, un ente híbrido, ya que al materializarse a través de la posesión su esencia está construida por lo carnal-humano y lo espiritual-demoníano. Esta figura, el demonio, «funciona como una metáfora de lo humano $[\ldots]$ y en realidad no es una criatura sobrenatural sino un motivo antropológico mediante el cual proyectamos, exteriorizamos y representamos el lado oscuro del hombre» (Thacker, 2015: 38). A diferencia de los dos monstruos anteriores aquí la humanidad del afectado se conserva en gran medida, o al menos es compartida con la presencia invasora. Esta dualidad ha hecho que la sensación de terror sea más intensa si cabe, ya que el poseído suele conservar su humanidad y, por tanto, su sufrimiento. Recordemos novelas que han sido llevadas con éxito al cine como The exorcist (1971), cuyo esquema se ha repetido hasta la saciedad. En cualquier caso, la posesión, tema terrorífico que se inscribe siempre en el ámbito de lo unipersonal, es planteada en la película Ava's possessions (2015), como un discurso "posterrorífico" y, por tanto, social. En este filme de Jordan Galland, su protagonista, Ava Dopkins, tras padecer una posesión demoníaca, debe asistir obligatoriamente a una terapia para poseídos (Poseídos Anónimos) como requisito impuesto por un juez si no quiere ingresar en prisión. El yonqui-zombi es aquí una suerte de poseído-alcohólico, que debe lidiar con las consecuencias de su posesión desde la terapia en grupo institucionalizada. El aporte más original de esta película se lo debemos a que quizá por vez primera se acepta que una posesión diabólica sea tratada por medios no religiosos o esotéricos sino terapéutico-sociales. El 
problema se desplaza de la esfera de lo oculto, privado y sobrenatural (al menos en gran parte) al ámbito de lo público, lo racional y lo social.

\section{CONClusiones}

En definitiva, en lo que coinciden estos tres tipos de narraciones es en proponer discursos "posterroríficos", en los que los monstruos han dejado de ser problemas en sí mismos, han sido superados como entidades ultraterrenas y sobrenaturales y han sido reciclados e incorporados al tejido social para reformular novedosos retos y dilemas, que trascienden la esfera individual para incorporarse a lo social. El vampiro ya no es un monstruo que solamente se te puede aparecer en tu solitaria alcoba (aunque también, como podría hacerlo cualquier asesino humano), sino que saciado de su sed de hemoglobina arrostra dilemas de integración social, posicionamiento en la jerarquía laboral y política, y en definitiva, trata de emanciparse de las sombras y los solitarios ataúdes para hacerse un hueco en la historia de los hombres. Los zombis, por su parte, enfermos que jamás habían sido escuchados y aquejados de un virus irreversible, tratan de lidiar con el trauma, el dolor propio y ajeno y sobre todo, tras haberse hallado una cura, intentan ser aceptados por los vecinos que un día fueron sus víctimas y sus meriendas. Algo similar ocurre con el endemoniado, quien, estigmatizado, jamás había gozado de una dimensión social, pero que ahora, según la peculiar cinta de Galland, quizá la única que plantea este dilema de recuperación terapéutica en sustitución del agua bendita, los rezos y la cruz, se considera un enfermo (sin negar la presencia de un demonio virulento) y por tanto una persona que puede y debe recuperarse mediante la correspondiente terapia.

Sintetizando se podría concluir que estos discursos "posterroríficos" se caracterizan por racionalizar el terror, intercambiando su naturaleza sobrenatural por problemas más reales (infecciones, virus...) o al menos más próximos a nuestra realidad social, familiar o política; también se definen por ensanchar el trauma personal a otros problemas de carácter social; y, finalmente, por humanizar al monstruo terrorífico y mostrarlo como un "humano inadaptado o problemático". Podemos añadir que otro de los rasgos que caracteriza a estos relatos posterroríficos lo constituye el hecho de que se le ha otorgado voz al monstruo, es decir, es portador de un discurso. Como han explicado tanto Campra (2008) como David Roas y Ana Casas (2016), respecto a algunas nuevas formas en la literatura fantástica, «una de estas innovaciones ha sido, indudablemente, la de darle la palabra a las criaturas del otro lado» (Campra, 2008: 148). Esta personificación y "humanización" del otro, juego entre alteridad e identidad, es una de las características también de estos relatos posterroríficos, que confieren al nuevo monstruo rasgos humanos, a la vez que se le ofrece la oportunidad del discurso. Roas y Casas atribuyen esta otorgación de voz al otro al «nuevo paradigma de la realidad y la visión posmoderna del sujeto» (2016: 197). 
Como exponíamos al inicio de este artículo, la realidad histórica es uno de los motores que mueve la definición genérica de la ficción fantástica. Los monstruos y el terror también sufren cambios, evolucionan y se adaptan a la sociedad, a los miedos y terrores que de ella emanan. Se observa que, no obstante, estas criaturas siguen conservando muchos de sus rasgos arquetípicos, rasgos que los constituyen como monstruos temibles, y también otros que los definen socialmente: el vampiro aristocrático que se siente superior al humano; la posesión satánica como metáfora de la alienación de la clase social media; y el zombi que metaforiza las clases más bajas e incómodas para el sistema capitalista. También hemos contemplando en nuestro análisis un caso peculiar de posterror (Les Revenants) en el que los elementos sobrenaturales se conservan, pero el ataque a los cimientos de la esfera social y emocional no deja de ser de gran impacto. Este peculiar caso podría considerarse como un eslabón (no cronológico aunque sí temático) que podría establecerse entre las ficciones terroríficas y posterroríficas. En las primeras, como ya hemos discutido, el efecto fantástico se mantiene y define sus propias naturalezas. En las últimas, lo fantástico se diluye y se abre paso a una nueva resignificación conceptual, a través de lecturas sociopolíticas, económicas y culturales. Además, esta peculiar serie de televisión se dimensiona gracias a la gran carga emocional que de su trama principal se desprende, la cual configura y da sentido a la obra en su totalidad.

En una sociedad cada vez más culta, agnóstica, científica e interconectada, es razonable que los estereotipos de los monstruos se hayan racionalizado, se humanicen y dejen de causar miedo sobrenatural. Entonces no queda otra alternativa que articular una nueva poética "posterrorífica", un cambio radical de paradigma, porque los monstruos clásicos morirán de viejos pero el terror y lo fantástico, con novedosas fórmulas, habrá de acompañarnos por muchos años.

\section{BibliogRAFÍA CITADA}

AlazRaki, Jaime (1983), En busca del unicornio: los cuentos de Julio Cortázar. Elementos para una poética de lo neofantástico, Madrid, Gredos.

Boluk, Stephanie y Wylie Lenz (2011), «Generation Z, the Age of Apocalypse», en W. Lenz y S. Boluk (eds.), Generation Zombie, Carolina del Norte, McFarland, págs. 1-17.

CAmpra, Rosalba (2008), Territorios de la ficción. Lo fantástico, Sevilla, Renacimiento.

CAsas, Ana (2012), «Prólogo» a A. Casas (ed.), Las mil caras del monstruo, Sevilla, Bracket Cultura, págs. 5-18.

Freud, Sigmund (1992), Obras Completas. XVII, Buenos Aires, Amorrortu Editores.

Hollinger, Veronica (1997), «Fantasies of absence: The postmodern vampire», en J. Gordon y V. Hollinger (eds.), Blood read: The vampire 
as metaphor in contemporary culture, Philadelphia, University of Pennsylvania Press, págs. 199-212.

JACKSOn, Rosemary (1986), Fantasy: Literatura y subversión, Buenos Aires, Catálogos Editora.

MARTínez DíAZ, Alicia (2010), «La vampirización del mito vampírico: del conde Drácula a Crepúsculo», en J. M. Losada Goya (coord.), Mito y mundo contemporáneo. La recepción de los mitos antiguos, medievales y modernos en la literatura contemporánea, Bari, Levanti Editori, págs. 124160.

PlatTs, Todd (2014), «The New Horror Movie», en B. Cogan y T. Gencarelly (eds.), Baby Boomers and Popular Culture. An inquiry into America's most powerful generation, California, Praeger, págs. 147-164.

RoAs, David (2001), «La amenaza de lo fantástico», en D. Roas (comp.), Teorías de lo fantástico, Madrid, Arco Libros, págs. 7-46.

RoAs, David (2011), Tras los límites de lo real. Una definición de lo fantástico, Madrid, Páginas de Espuma.

ROAS, David y Ana CASAS (2016), Voces de lo fantástico en la narrativa española contemporánea, Málaga, EDA Libros.

SÁnchez Trigos, Rubén (2013), «Muertos, infectados y poseídos: el zombi en el cine español contemporáneo», Pasavento, 1/1, págs. 1134.

ThaCKer, Eugene (2015), En el polvo de este mundo, Madrid, Materia Oscura.

Trapero Llobera, Patricia (2015), «Todos los monstruos son humanos: el imaginario cultural y la creación de bestiarios contemporáneos en American Horror Story», Brumal, 3/2, págs. 69-88.

Fecha de recepción: 19/04/2019.

Fecha de aceptación: 17/07/2019. 